\title{
A randomised trial of the pharmacodynamic and pharmacokinetic effects of ticagrelor compared with clopidogrel in Hispanic patients with stable coronary artery disease
}

\author{
Matthew J. Price • Leonardo Clavijo • \\ Dominick J. Angiolillo • Glenn Carlson • \\ Richard Caplan $\cdot$ Renli Teng $\cdot$ Juan Maya
}

Published online: 11 October 2014

(C) The Author(s) 2014. This article is published with open access at Springerlink.com

\begin{abstract}
The objective was to compare the pharmacodynamic (PD) and pharmacokinetic (PK) effects of ticagrelor with clopidogrel among subjects of Hispanic ethnicity, as the PD and PK effects of antiplatelet agents among Hispanics are not specifically known. This was a randomised, open-label, crossover PD/PK study of 40 Hispanic subjects with stable coronary artery disease (CAD). Subjects were allocated to either ticagrelor $180 \mathrm{mg}$ loading dose (LD)/90 mg twicedaily maintenance dose (MD) followed by clopidogrel $600 \mathrm{mg} \mathrm{LD} / 75 \mathrm{mg}$ once-daily MD with an intervening washout period, or vice versa. The primary endpoint was ontreatment reactivity (OTR) at $2 \mathrm{~h}$ post-LD according to the VerifyNow P2Y12 test. OTR was significantly lower at $2 \mathrm{~h}$ post-LD with ticagrelor compared with clopidogrel (34 PRU
\end{abstract}

The author Juan Maya was an AZ employee at time of study completion.

Electronic supplementary material The online version of this article (doi:10.1007/s11239-014-1135-9) contains supplementary material, which is available to authorized users.

M. J. Price $(\bowtie)$

10666 North Torrey Pines Road, Maildrop S1056, La Jolla, CA 92037, USA

e-mail: price.matthew@scrippshealth.org

L. Clavijo

Division of Cardiology, Keck School of Medicine, University of

Southern California, 1510 San Pablo Street, Suite 322,

Los Angeles, CA 90033, USA

e-mail: Leonardo.Clavijo@med.usc.edu

D. J. Angiolillo

Division of Cardiology, Department of Medicine, University of Florida College of Medicine-Jacksonville, Shands Jacksonville, 655 West 8th St, Jacksonville, FL 32209, USA

e-mail: dominick.angiolillo@jax.ufl.edu vs. $201 \mathrm{PRU}$, least square means difference $=-167 \mathrm{PRU}$ [95\% CI, $-197,-137$ ], $P<0.001)$. OTR was also lower with ticagrelor at $30 \mathrm{~min}$ and $8 \mathrm{~h}$ post-LD $(P<0.001)$. The greater magnitude of antiplatelet effect with ticagrelor persisted after 7 days of MD (52 PRU [95\% CI, 30, 73] vs. 182 PRU [95 \% CI, 160, 205], $P<0.001)$. Mean plasma concentration of ticagrelor and its active metabolite were greatest at $2 \mathrm{~h}$ post-LD, with similar levels at $2 \mathrm{~h}$ post-MD after 7 days of MD. Among Hispanic subjects with stable $\mathrm{CAD}$, ticagrelor provides a more rapid onset of platelet inhibition and a significantly greater antiplatelet effect compared with clopidogrel during both the loading and maintenance phases of treatment.

Keywords Platelet reactivity - Ticagrelor - Clopidogrel · Hispanic $\cdot$ Coronary artery disease

G. Carlson · R. Caplan $\cdot$ R. Teng $\cdot$ J. Maya

AstraZeneca LP, 1800 Concord Pike,

P.O. Box 15437, Wilmington, DE 19850-5437, USA

e-mail: Glenn.carlson@astrazeneca.com

R. Caplan

e-mail: Richard.caplan@astrazeneca.com

R. Teng

e-mail: Renli.teng@astrazeneca.com

J. Maya

e-mail: Maya.juan1@gmail.com 


\section{Introduction}

Coronary artery disease (CAD) and acute coronary syndrome (ACS) are leading causes of mortality in the United States [1]. Interventions that may reduce the incidence of ACS or mitigate its sequelae are therefore of substantial societal benefit. However, the populations evaluated in most randomised cardiovascular outcomes trials do not reflect the broad range of ethnicities to which the therapies studied may be subsequently applied in clinical practice. Engaging under-represented communities in research and identifying patient subgroups whose response to a given therapy may differ from that of the average patient in a trial are priorities for scientific research and investment [2]. Hispanics in the United States have higher rates of diabetes mellitus, metabolic syndrome and obesity than non-Hispanic whites, have a substantial burden of cardiovascular disease, and are a growing fraction of the national population. Ticagrelor is an oral platelet $\mathrm{P}_{2} \mathrm{Y}_{12^{-}}$ receptor antagonist that significantly reduces major cardiovascular events after ACS compared with clopidogrel, driven by reductions in myocardial infarction and cardiovascular death, without a significant increase in all-cause major bleeding, although non-coronary artery bypass grafting related bleeding is increased [3]. We sought to evaluate the antiplatelet effects of ticagrelor compared with clopidogrel in Hispanic subjects with established CAD.

\section{Materials and methods}

\section{Study design}

This was a randomised, open-label, crossover study conducted at six sites within the United States (See Online Appendix for study sites). The study was approved by the Institutional Review Boards at all sites and was conducted in accord with the provisions of the Declaration of Helsinki. All subjects provided written, informed consent (clinicaltrials.gov identifier, NCT01523366).

\section{Study population}

Subjects were eligible to be enrolled if they were a Hispanic male or female $\geq 18$ years of age, were receiving aspirin 75-100 mg daily maintenance dose (MD), and had documented stable CAD according to one of the following criteria: (a) current or history of stable angina with objective evidence of CAD; (b) prior myocardial infarction; or (c) prior surgical or percutaneous coronary revascularisation. Hispanic ethnicity was based upon self-identification. Major exclusion criteria included any indication for oral anticoagulation or dual antiplatelet therapy, and concomitant therapy with strong CYP3A4 inhibitors or inducers.
Detailed inclusion and exclusion criteria and participating sites are listed in the Online Appendix.

Study procedures

Subjects were randomised 1:1 to receive one of two possible treatment sequences: either open-label clopidogrel in the first period followed by open-label ticagrelor in the second period or vice versa (Fig. 1). There was a 10-14 days washout between periods. Clopidogrel was administered as a $600 \mathrm{mg}$ loading dose (LD) followed by a $75 \mathrm{mg}$ once-daily MD for 7-9 days, and ticagrelor was administered as a $180 \mathrm{mg}$ LD followed by a $90 \mathrm{mg}$ twice-daily MD for 7-9 days. Subjects received aspirin 75-100 mg once-daily, which was maintained at a constant dose throughout the study. To evaluate the onset of anti-platelet effect, platelet reactivity was assessed at baseline prior to the $\mathrm{LD}$ and at 0.5 , 2 and $8 \mathrm{~h}$ after the LD; to evaluate the effect of the MD, platelet reactivity was assessed just prior to, 2 , and $8 \mathrm{~h}$ after the last morning dose, and $12 \mathrm{~h}$ after the last evening dose of ticagrelor and $24 \mathrm{~h}$ after the last morning dose of clopidogrel. Blood samples to analyse the plasma concentrations of ticagrelor and its active metabolite, AR-C124910XX, were drawn at the same time as platelet reactivity assessment.

\section{Platelet reactivity measurement}

Platelet reactivity was assessed using the VerifyNow P2Y12 test, which measures adenosine diphosphateinduced platelet aggregation as an increase in light transmittance and reports values in $\mathrm{P} 2 \mathrm{Y} 12$ reaction units (PRU). A higher PRU reflects greater platelet reactivity [4]. Although study treatment was open-label, the PRU results were blinded to study personnel.

\section{Definitions and endpoints}

The primary endpoint was the inhibition of the platelet $\mathrm{P}_{2} \mathrm{Y}_{12}$ receptor at $2 \mathrm{~h}$ after the $\mathrm{LD}$, as measured by least squares (LS) means difference in PRU. Secondary endpoints included the PRU at 0.5 and $8 \mathrm{~h}$ after the LD; the PRU at $2,8 \mathrm{~h}$, and the end-of-dosing interval of the MD (12 $\mathrm{h}$ after last evening dose for ticagrelor or $24 \mathrm{~h}$ after last dose of clopidogrel); and the percent reduction of PRU from baseline at the time-points measured, i.e. (1 - [PRU after study drug/PRU at baseline]) $\times 100$.

Statistical analysis

Categorical variables are reported as counts and percentages, and continuous variables as mean \pm standard deviation (SD). The primary analysis of the difference in PRU between ticagrelor and clopidogrel at $2 \mathrm{~h}$ after the LD was 


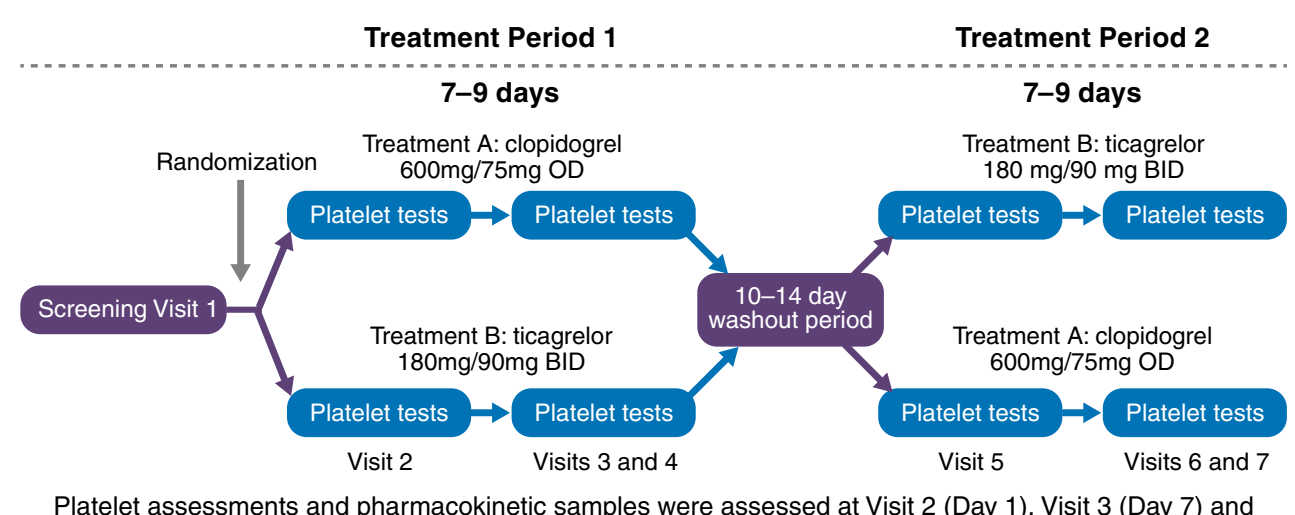

Visit 4 (Day 8) in Treatment Period 1 and Visit 5 (Day 1), Visit 6 (Day 7) and Visit 7 (Day 8) in Treatment Period 2

Fig. 1 Study design. Hispanic subjects with CAD and treated with aspirin therapy were randomly assigned in a 1:1 fashion to one of two treatment sequences: either ticagrelor $180 \mathrm{mg} \mathrm{LD}$ and $90 \mathrm{mg}$ twicedaily MD for 7-9 days, followed by a washout period and clopidogrel $600 \mathrm{mg} \mathrm{LD}$ and $75 \mathrm{mg}$ once-daily MD for 7-9 days, or clopidogrel $600 \mathrm{mg}$ LD and $75 \mathrm{mg}$ once-daily MD for 7-9 days, followed by a

performed using a mixed-effect model with fixed effects for period, treatment sequence, treatment, and a random effect for patient within sequence. Mean on-treatment reactivity was estimated using LS means and two-sided $95 \%$ confidence intervals (CIs). Distribution assumptions underlying the analysis were assessed by residual plots. Secondary analyses of on-treatment reactivity at other timepoints were performed with similar mixed effects models. Several sensitivity analyses were performed. In one pre-specified analysis, platelet reactivity at baseline was included as a fixed effect. In addition, a post hoc analysis was performed including treatment periods in which the baseline on-treatment reactivity prior to study drug administration was $<150 \mathrm{PRU}$, which was thought to be due to incomplete washout of study drug.

A sample size of 12 subjects was required to provide $90 \%$ power to detect a difference in on-treatment reactivity of 100 PRU between ticagrelor and clopidogrel at $2 \mathrm{~h}$ post-LD, assuming a SD of $93 \mathrm{PRU}$, a correlation of 0.5 between paired observations, and a two-sided alpha level of 0.05. Based on a need to enrol a cohort of sufficient size for clinical credibility and to evaluate $\mathrm{P}_{2} \mathrm{Y}_{12}$ receptor inhibition at secondary timepoints and to collect potential adverse events, it was planned that 34 subjects would be enrolled in order to ensure 28 subjects were evaluable. This would provide more than $99 \%$ power to detect the anticipated primary outcome effect.

\section{Results}

Study flow is shown in Fig. 2. A total of 40 subjects were randomised. All subjects received at least one dose of ticagrelor and 39 subjects received at least one dose of washout period and ticagrelor $180 \mathrm{mg}$ LD and $90 \mathrm{mg}$ twice-daily MD for 7-9 days. Platelet reactivity assessment and ticagrelor plasma concentrations were measured at several timepoints around the LD and at the end of the MD phase. $C A D$ coronary artery disease, $L D$ loading dose, $M D$ maintenance dose

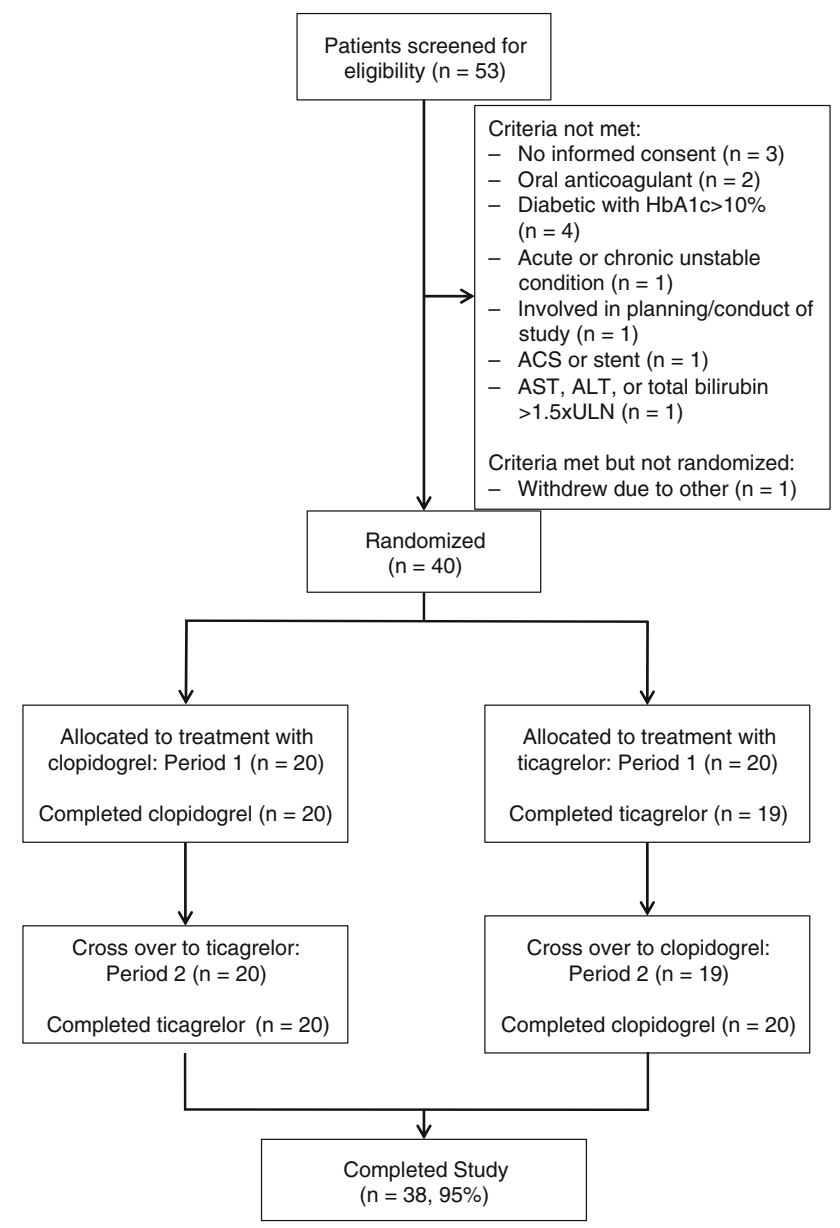

Fig. 2 Study flow. A total of 40 subjects were randomly assigned to a treatment sequence, of which 39 completed at least one follow-up visit and of which 38 completed at least 7 days of the maintenance dosing phase for both study drugs 
Table 1 Demographics and clinical characteristics of the study population

\begin{tabular}{ll}
\hline & Total $(N=40)$ \\
\hline Age (years), mean $\pm \mathrm{SD}$ & $63.8 \pm 8.8$ \\
Age $\geq 65$ (years), $n(\%)$ & $18(45)$ \\
Male sex, $n(\%)$ & $28(70)$ \\
Hypertension, $n(\%)$ & $38(95)$ \\
Dyslipidaemia, $n(\%)$ & $39(98)$ \\
Diabetes mellitus, $n(\%)$ & $21(53)$ \\
Body mass index, mean $\pm \mathrm{SD}$ & $30.2 \pm 5.3$ \\
Heart failure, $n(\%)$ & $3(8)$ \\
Prior myocardial infarction, $n(\%)$ & $26(65)$ \\
Prior percutaneous coronary intervention, $n(\%)$ & $32(80)$ \\
\hline
\end{tabular}

SD standard deviation

clopidogrel. A total of 38 subjects completed the study. Clinical characteristics and demographics of the randomised subjects are shown in Table 1 . The mean age was $63.8 \pm 8.8$ years, 28 subjects $(70 \%)$ were male, $21(53 \%)$ had diabetes mellitus, and $26(65 \%)$ had a prior myocardial infarction. Data from three subjects with baseline ontreatment reactivity $<150$ PRU were excluded from the primary analysis, as this observation was felt to be consistent with an incomplete washout from a $\mathrm{P}_{2} \mathrm{Y}_{12}$ antagonist and/or the presence of an interfering agent. These values were included in a post hoc sensitivity analysis.

Pharmacodynamic effects of ticagrelor and clopidogrel

The antiplatelet effect of study drug LD is shown in Table 2 and Fig. 3. At $2 \mathrm{~h}$ post-LD, the primary endpoint of the study, on-treatment reactivity was significantly lower after ticagrelor compared with clopidogrel (LS means difference, -167 PRU [95 \% CI $-197,-137], P<0.001)$. This greater anti-platelet effect was evident within $30 \mathrm{~min}$ after the LD and persisted at $8 \mathrm{~h}$ after the LD (Table 2). The antiplatelet effects of ticagrelor $90 \mathrm{mg}$ twice-daily MD and clopidogrel $75 \mathrm{mg}$ once-daily MD after 7-9 days of dosing are shown in Table 3 and Fig. 3. On-treatment reactivity was significantly lower with ticagrelor compared with clopidogrel $2 \mathrm{~h}$ and $8 \mathrm{~h}$ after the MD, and was significantly lower at the end of the dosing interval $(12 \mathrm{~h}$ after the last ticagrelor MD and $24 \mathrm{~h}$ after the last clopidogrel MD). On sensitivity analysis, the primary results were similar when data from the three subjects with abnormally low baseline reactivity were included (LS means difference at $2 \mathrm{~h}$ post-LD between ticagrelor and clopidogrel, -154.4 PRU [95 \% CI $-187.4,-121.4], P<0.001)$. The results of other sensitivity analyses were also similar to the primary analysis (see Online Appendix.)

Pharmacokinetic profiles of ticagrelor and its metabolite, AR-C124910XX

The pharmacokinetic (PK) profiles of ticagrelor and ARC124910XX during the LD and MD phases are shown in Table 4. There was a rapid onset of circulating ticagrelor, and the concentration was greatest at the 2-hour post-LD measurement. After repeated dosing during the maintenance phase of treatment, the mean ticagrelor plasma concentration $2 \mathrm{~h}$ after a MD was generally consistent with that at $2 \mathrm{~h}$ after the $\mathrm{LD}$.

\section{Adverse events}

There were no serious adverse events, bleeding events, or other adverse events that led to discontinuation of study medication.

\section{Discussion}

This is the first randomised, pharmacodynamic (PD) and PK study to specifically compare the antiplatelet effect of ticagrelor and clopidogrel in a pre-defined and statistically powered population of Hispanic patients with stable CAD. We demonstrate that among Hispanic subjects with stable CAD on low-dose aspirin, a ticagrelor $180 \mathrm{mg} \mathrm{LD}$ has a more rapid onset of effect compared with clopidogrel $600 \mathrm{mg} \mathrm{LD}$, and that within $30 \mathrm{~min}$, ticagrelor reduced platelet reactivity to a significantly greater extent than clopidogrel, an effect that persisted during the maintenance

Table 2 Comparative antiplatelet effect of ticagrelor $180 \mathrm{mg}$ LD compared with clopidogrel $600 \mathrm{mg}$ LD in Hispanic subjects with CAD

\begin{tabular}{lcccr}
\hline Timepoint & Ticagrelor $180 \mathrm{mg} \mathrm{LD}$ & Clopidogrel $600 \mathrm{mg}$ LD & LS means difference & $P$ value \\
\hline $\begin{array}{l}\text { Primary endpoint } \\
2 \text { h post-LD }(95 \% \mathrm{CI})\end{array}$ & $34(12,56)$ & $201(179,224)$ & $-167(-197,-137)$ & $<0.001$ \\
$\begin{array}{l}\text { Secondary endpoints } \\
0.5 \text { h post-LD }(95 \% \mathrm{CI})\end{array}$ & $135(105,164)$ & $270(239,301)$ & $-135(-172,-98.0)$ & $<0.001$ \\
8 h post-LD $(95 \% \mathrm{CI})$ & $34(9,59)$ & $203(177,229)$ & $-169(-204,-134)$ & $<0.001$ \\
\hline
\end{tabular}

All measurements are in PRU

$C A D$ coronary artery disease, $C I$ confidence interval, $L D$ loading dose, $L S$ least squares, $P R U$ P2Y12 reaction unit 

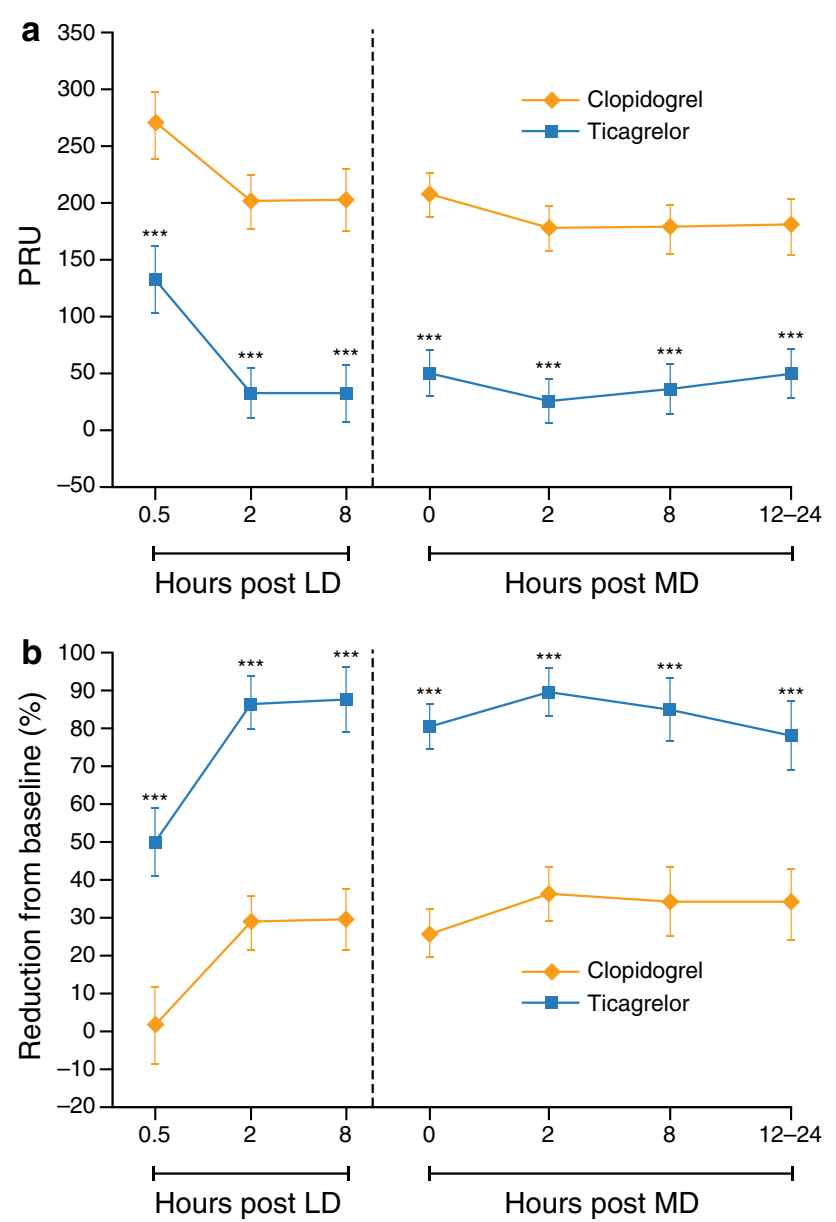

Fig. 3 On-treatment platelet reactivity on ticagrelor and clopidogrel in Hispanic subjects with CAD receiving low-dose aspirin. a Ontreatment reactivity at baseline and after a ticagrelor $180 \mathrm{mg} \mathrm{LD}$ or clopidogrel $600 \mathrm{mg}$ LD and after 7-9 days of MD therapy with ticagrelor $90 \mathrm{mg}$ twice daily or clopidogrel $75 \mathrm{mg}$ once daily. b Percentage reduction from baseline in on-treatment reactivity after a ticagrelor $180 \mathrm{mg}$ LD or clopidogrel $600 \mathrm{mg} \mathrm{LD}$ and after 7-9 days of MD with ticagrelor $90 \mathrm{mg}$ twice daily or clopidogrel $75 \mathrm{mg}$ once daily. Values are expressed as the least square means and $95 \%$ confidence intervals. $L D$ loading dose, $M D$ maintenance dose. $* * * P<0.001$

phase of treatment. The PK of ticagrelor and its metabolite AR-C124910XX were consistent with these findings.

The antiplatelet onset of ticagrelor and its effect during the maintenance phase compared with that of clopidogrel was previously evaluated by Gurbel et al. [5], who reported no subjects of Hispanic ethnicity. In that study, on-treatment reactivity measured by PRU was significantly lower in the ticagrelor group at all assessed times in the first $24 \mathrm{~h}$ after loading and during the maintenance phase. In the current study, the mean on-treatment reactivity with ticagrelor $180 \mathrm{mg}$ LD/90 mg twice-daily MD was significantly lower than clopidogrel $600 \mathrm{mg}$ LD/75 mg oncedaily $\mathrm{MD}$ at all measured times starting $30 \mathrm{~min}$ after the loading dose. Specifically, the mean on-treatment reactivity was 135 PRU lower 30 min after the LD, 167 PRU lower $2 \mathrm{~h}$ after the loading dose $(P<0.001)$, and 131 PRU lower at the time of the next scheduled maintenance dose; these differences are similar to the VerifyNow P2Y12 test results reported by Gurbel et al. [5]. Plasma concentrations of ticagrelor and AR-C124910XX were also consistent with those observed in previous studies of ticagrelor. Therefore, although we did not directly compare the PD and PK of ticagrelor in Hispanics with non-Hispanics, the antiplatelet effect of ticagrelor among Hispanics appears to be consistent with that observed among the non-Hispanics that make up the bulk of subjects upon which the prior reported experience is based.

Racial and ethnic disparities in cardiovascular care are important public health issues. For example, Hispanic patients have longer delays to reperfusion than non-Hispanic Whites [6]; non-Whites, including Hispanics, presenting with ACS have worse prognosis [7]; and MexicanAmericans are at higher risk of cardiovascular mortality at younger ages than non-Hispanic Whites [8]. The disparity in cardiovascular care also extends to the conduct of randomised, clinical trials. In the PLATO study there was a trend towards higher overall event rates among 1,237 patients with ACS included in Central/South America, as compared to patients included in Asia/Australia, Europe/ Middle East/Africa or North America. However, the overall results for primary efficacy and safety were consistent in patients included in Central/South America [3]. The present study, which demonstrates a fast and consistent effect on platelet aggregation, support the observation from PLATO. PD studies such as the current one provide important confirmatory data that the response to ticagrelor

Table 3 Comparative antiplatelet effect of ticagrelor compared with clopidogrel maintenance dosing in Hispanic subjects with CAD

\begin{tabular}{|c|c|c|c|c|}
\hline Timepoint & Ticagrelor $180 \mathrm{mg}$ LD & Clopidogrel 600 mg LD & LS means difference & $P$ value \\
\hline End of dosing interval ${ }^{\mathrm{a}}(95 \% \mathrm{CI})$ & $52(30,73)$ & $182(160,205)$ & $-131(-158,-103)$ & $<0.001$ \\
\hline $2 \mathrm{~h}$ after dose $(95 \% \mathrm{CI})$ & $29(8,49)$ & $179(158,200)$ & $-151(-177,-124)$ & $<0.001$ \\
\hline $8 \mathrm{~h}$ after dose $(95 \% \mathrm{CI})$ & $39(17,60)$ & $179(157,201)$ & $-140(-168,-112)$ & $<0.001$ \\
\hline
\end{tabular}

All measurements are in PRU. Platelet reactivity was assessed at least 7 days of maintenance dosing (ticagrelor 90 mg twice daily and clopidogrel $75 \mathrm{mg}$ once daily)

$C A D$ coronary artery disease, $L D$ loading dose, $L S$ least squares

a $12 \mathrm{~h}$ after last evening dose of ticagrelor and $24 \mathrm{~h}$ after the last morning dose of clopidogrel 
Table 4 Plasma concentrations of ticagrelor and its active metabolite, AR-C124910XX

\begin{tabular}{|c|c|c|c|c|c|c|}
\hline & \multicolumn{3}{|l|}{ Post-LD } & \multicolumn{3}{|l|}{ Post-MD } \\
\hline & $0.5 \mathrm{~h}$ & $2 \mathrm{~h}$ & $8 \mathrm{~h}$ & $2 \mathrm{~h}$ & $8 \mathrm{~h}$ & End of MD dosing interval \\
\hline \multicolumn{7}{|l|}{ Ticagrelor } \\
\hline Geometric mean-SD & 23.6 & 126.9 & 234.7 & 142.9 & 151.3 & 64.6 \\
\hline Geometric mean $+\mathrm{SD}$ & 1023.2 & 3976.8 & 775.2 & 1975.3 & 684.5 & 863.4 \\
\hline Arithmetic mean \pm SD & $381.8 \pm 78.0$ & $1,147.4 \pm 644.1$ & $502.1 \pm 301.5$ & $747.9 \pm 428.7$ & $404.8 \pm 289.3$ & $370.5 \pm 353.4$ \\
\hline \multicolumn{7}{|l|}{ AR-C124910XX } \\
\hline Geometric mean-SD & 2.2 & 39.5 & 42.8 & 31.7 & 36.7 & 19.9 \\
\hline Geometric mean + SD & 58.0 & 662.9 & 258.5 & 554.4 & 298.4 & 346.9 \\
\hline Arithmetic mean $\pm \mathrm{SD}$ & $31.8 \pm 50.0$ & $243.4 \pm 141.5$ & $127.4 \pm 57.7$ & $206.9 \pm 133.6$ & $135.3 \pm 66.6$ & $126.9 \pm 71.6$ \\
\hline
\end{tabular}

$N=37$, except $2 \mathrm{~h}$ post-LD and the end of MD dosing interval, where $N=36$. Units are $\mathrm{ng} / \mathrm{ml}$. Refer to the methods for a description of how the geometric mean was calculated

End of MD dosing interval was $12 \mathrm{~h}$ the last evening dose after 7 days of study drug administration

$L D$ loading dose, $M D$ maintenance dose, $S D$ standard deviation

does not appear to differ among this ethnic subgroup. The consistent observations with our PK analysis, which track the PD profile, support these findings. Robust demographic data collection in clinical practice combined with comparative effectiveness studies are required to fully explore whether there are substantial differences in clinical efficacy among population subsets. Further studies are also needed to assess the PD effect and clinical efficacy of antiplatelet agents within ethnicities that have a substantial burden of CAD but are not well-represented in large, randomised, clinical trials.

This study has several limitations. The present study was not designed to examine the relation of clinical outcomes and platelet function. Subjects were self-identified as Hispanic. This follows the policy of the United States Food and Drug Administration for the collection of race and ethnicity, as well as that of the United States Department of Health and Human Services. We evaluated patients with stable CAD, and the PD and PK of ticagrelor and clopidogrel may differ among patients with ACS. Of note, the subjects in this study were a higher-risk CAD cohort, as two-thirds had a prior history of myocardial infarction, $80 \%$ had prior percutaneous coronary intervention, $33 \%$ had prior coronary artery bypass grafting, and diabetes mellitus was present in more than half. The Prevention of Cardiovascular Events in Patients With Prior Heart Attack Using Ticagrelor Compared to Placebo on a Background of Aspirin (PEGASUS)-TIMI 54 trial (clinicaltrials.gov identifier, NCT01225562) will examine the safety and efficacy of ticagrelor in combination with low-dose aspirin in patients with a prior myocardial infarction and an additional risk factor, including diabetes mellitus or multivessel disease; therefore, the findings of the current study may provide insight into the anticipated PD and PK of the ticagrelor $90 \mathrm{mg}$ twice-daily MD being examined within that trial.

\section{Conclusion}

Among Hispanic subjects with stable CAD, a ticagrelor $180 \mathrm{mg}$ LD followed by $90 \mathrm{mg}$ twice-daily MD provides a more rapid onset of platelet inhibition and a significantly greater antiplatelet effect compared with clopidogrel $600 \mathrm{mg}$ LD followed by $75 \mathrm{mg}$ once-daily MD during both the loading and maintenance phases of treatment. The PK profiles of ticagrelor and its metabolite AR-C124910XX were consistent with these findings.

Acknowledgments Editorial assistance in formatting the manuscript for submission was provided by Logan Westbrook of GardinerCaldwell Communications, and was funded by AstraZeneca, LP. This study was funded by AstraZeneca. Editorial assistance in formatting the manuscript for submission was funded by AstraZeneca, LP.

Conflict of interest This study was funded by AstraZeneca, LP. Dr Price reports receipt of consulting honoraria from AstraZeneca, Daiichi-Sankyo/Eli Lilly \& Co., Janssen Pharmaceuticals, Medicure, and The Medicines Company, speaker's fees from AstraZeneca and Daiichi-Sankyo/Eli Lilly \& Co., and equity interest in Iverson Genetics. Dr Angiolillo has received payment as an individual for consulting fee or honorarium from Bristol-Myers Squibb, SanofiAventis, Eli Lilly, Daiichi Sankyo, Inc., The Medicines Company, AstraZeneca, Merck, Evolva, Abbott Vascular, and PLx Pharma, and participation in review activities from Johnson \& Johnson, St. Jude, and Sunovion, and has received institutional payments for Grants from Bristol-Myers Squibb, Sanofi-Aventis, GlaxoSmithKline, Otsuka, Eli Lilly, Daiichi Sankyo, Inc., The Medicines Company, AstraZeneca and Gilead. Dr Clavijo reports receipt of consulting honoraria from AstraZeneca and Medtronic, Speaker's fees from Daiichi-Sankyo/Eli Lilly and Medtronic, and received institutional Grant support from AstraZeneca, Abbott Vascular, Medtronic and Roche. Dr Carlson, Dr Caplan and Dr Teng are current employees of 
AstraZeneca, LP. Dr Maya was employed by AstraZeneca, LP at the time of study completion.

Open Access This article is distributed under the terms of the Creative Commons Attribution License which permits any use, distribution, and reproduction in any medium, provided the original author(s) and the source are credited.

\section{References}

1. Go AS, Mozaffarian D, Roger VL, Benjamin EJ, Berry JD, Borden WB, Bravata DM, Dai S, Ford ES, Fox CS, Franco S, Fullerton HJ, Gillespie C, Hailpern SM, Heit JA, Howard VJ, Huffman MD, Kissela BM, Kittner SJ, Lackland DT, Lichtman JH, Lisabeth LD, Magid D, Marcus GM, Marelli A, Matchar DB, McGuire DK, Mohler ER, Moy CS, Mussolino ME, Nichol G, Paynter NP, Schreiner PJ, Sorlie PD, Stein J, Turan TN, Virani SS, Wong ND, Woo D, Turner MB, American Heart Asssociation Statistics Committee and Stroke Statistics Subcommittee (2013) Heart disease and stroke statistics-2013 update: a report from the American Heart Association. Circulation 127:e6-e245

2. Conway PH, Clancy C (2009) Comparative-effectiveness research-implications of the Federal Coordinating Council's Report. N Engl J Med 361:328-330

3. Wallentin L, Becker RC, Budaj A, Cannon CP, Emanuelsson H, Held C, Horrow J, Husted S, James S, Katus H, Mahaffey KW,
Scirica BM, Skene A, Steg PG, Storey RF, Harrington RA, PLATO Investigators, Freij A, Thorsén M (2009) Ticagrelor versus clopidogrel in patients with acute coronary syndromes. N Engl J Med 361:1045-1057

4. Price MJ (2009) Bedside evaluation of thienopyridine antiplatelet therapy. Circulation 119:2625-2632

5. Gurbel PA, Bliden KP, Butler K, Tantry US, Gesheff T, Wei C, Teng R, Antonino MJ, Patil SB, Karunakaran A, Kereiakes DJ, Parris C, Purdy D, Wilson V, Ledley GS, Storey RF (2009) Randomized double-blind assessment of the ONSET and OFFSET of the antiplatelet effects of ticagrelor versus clopidogrel in patients with stable coronary artery disease: the ONSET/OFFSET study. Circulation 120:2577-2585

6. Bradley EH, Herrin J, Wang Y, McNamara RL, Webster TR, Magid DJ, Blaney M, Peterson ED, Canto JG, Pollack CV Jr, Krumholz HM (2004) Racial and ethnic differences in time to acute reperfusion therapy for patients hospitalized with myocardial infarction. JAMA 292:1563-1572

7. Sabatine MS, Blake GJ, Drazner MH, Morrow DA, Scirica BM, Murphy SA, McCabe CH, Weintraub WS, Gibson WS, Cannon CP (2005) Influence of race on death and ischemic complications in patients with non-ST-elevation acute coronary syndromes despite modern, protocol-guided treatment. Circulation 111:1217-1224

8. Hurley LP, Dickinson LM, Estacio RO, Steiner JF, Havranek EP (2010) Prediction of cardiovascular death in racial/ethnic minorities using Framingham risk factors. Circ Cardiovasc Qual Outcomes 3:181-187 